\title{
Funções desempenhadas pelos websites de bibliotecas jurídicas governamentais brasileiras
}

\author{
Sueli Angelica do Amaral \\ Katyusha Madureira Loures de Souza *
}

Artículo recibido:

1 de abril de 2008.

Artículo aceptado:

29 de agosto de 2008.

\section{RESUMEN}

Describe las funciones desempeñadas por los websites de 38 bibliotecas jurídicas gubernamentales brasileñas, incluyendo en este universo a las bibliotecas del Senado Federal, de la Cámara de Diputados, de las Asambleas Legislativas, de los Ministerios públicos y de los Tribunales. La observación de los websites se llevó a cabo por medio de una lista de verificación que cotejó las funciones desempeñadas por los websites según una clasificación de esas funciones en seis categorías: informativa, promocional, educativa, referencial y de investigación y comunicación. Los resultados del análisis destacaron niveles diferenciados en el desempeño de las funciones de los websites analizados. Una función informativa se

* Las dos autoras pertenecen a la Universidade de Brasília, Brasil. (Sueli: samaral@ unb.br); (Katyusha: katyushams@yahoo.com.br).

INVESTIGACIÓN BIBLIOTECOLÓGICA, Vol. 22, Núm. 46, septiembre/diciembre, 2008, México, ISSN: 0187-358X. pp. 165-186 
destacó como la de mejor desempeño; y se identificó un bajo índice de desempeño en la función de comunicación.

Palabras clave: Websites; Funciones; Bibliotecas jurídicas; Bibliotecas legislativas, Brasil.

\begin{abstract}
Performance of Brazillian government juridical library websites

Sueli Angelica do Amaral and Katyusha Madureira Loures de Souza

The paper describes the functional performance of 38 websites of Brazilian government law libraries, including those of the Federal Senate, the Chamber of Deputies, the Legislative Assembly, Public Ministries and Courts. A checklist was used to verify six categories of functions: informational, promotional, educational, referential, research and communication. Results underline different performance levels: Information function highlights as the best performer while the communication function achieved a low score.
\end{abstract}

Keywords: Websites; Funcions; Law libraries, Brazil.

\title{
INTRODUÇÃO
}

\begin{abstract}
A o marcar presença na Internet por meio do seu website, a biblioteca po$\mathrm{A}_{\text {de atender de forma mais adequada às necessidades de seus usuários e }}$ oferecer um atrativo a mais para sua clientela. Por essa razão e pela importância fundamental que a informação adquiriu, é imperativo utilizar o website como ferramenta capaz de representar a biblioteca na Web com melhor desempenho na sua ação de organização prestadora de serviços de informação.

Neste sentido, Amaral e Guimarães (2002) apresentaram proposta de classificação das funções desempenhadas pelos websites de bibliotecas, que foi testada em websites de bibliotecas brasileiras de instituições de ensino superior.

No âmbito das bibliotecas jurídicas, são praticamente inexistentes os estudos sobre os websites dessas bibliotecas. Assim, foi realizada uma pesquisa para verificar o desempenho das funções dos websites das bibliotecas jurídicas
\end{abstract}


governamentais brasileiras com a aplicação da mesma classificação utilizada para a pesquisa sobre o desempenho das funções dos websites das bibliotecas brasileiras de instituições de ensino superior.

\section{INTERNET E WEBSITES DE BIBLIOTECAS}

Muitos confundem a Internet com a web, talvez porque a web seja parte da Internet, mas os termos têm significados diferentes.

A Internet é a maior rede de comunicação, capaz de interligar uma rede de computadores com abrangência mundial, englobando milhares de redes menores baseadas em protocolos de redes. É o meio físico de comunicação. Já a web é um sistema de informações organizado de maneira a englobar todos os outros sistemas de informação disponíveis na Internet. A web é o sistema que incorpora a Internet. $\mathrm{O}$ usuário conectado à Internet poderá navegar na web por meio de um software específico, denominado browser ou navegador.

Ao estabelecer uma conexão com a Internet, o usuário passa a ter possibilidade de se comunicar com qualquer outro computador conectado à rede. Isto não significa que esteja realmente se comunicando, pois para isso é necessário utilizar um dos serviços disponíveis na Internet. Estar presente na Internet, por meio de um website, significa abrir novas oportunidades, pois o tempo e o espaço adquirem conceitos diferentes.

Segundo o Livro Verde da Sociedade da Informação no Brasil, site é uma "coleção de páginas da Web referentes a um assunto, instituição, empresa, pessoa etc." (Sociedade, 2000, p.175). Entretanto, no Brasil, os termos site, website, web site, site web e sítio são utilizados indistintamente na literatura. Assim, neste estudo não foi adotado um termo padrão, considerando essas divergências terminológicas.

Chaim (2001, p. 8) lembra que

na Internet, o website funciona como o objeto que agrega conteúdo, informações, estratégias. Utiliza aplicações e tecnologias utilitárias residentes no provedor de serviço Internet que possibilitam, por exemplo, resguardar a produção intelectual, limitar a produção de cópias em papel, conhecer os consumidores da informação, personalizar conteúdos em função das necessidades do público-alvo e interagir com a comunidade que o freqüenta.

A Internet trouxe complexidades antes não existentes quanto ao material impresso, tais como: "volatilidade, abertura, mutabilidade, dinamismo espaçotemporal" (Silva e Tomaél, 2004, p. 8). Apesar de sua magnitude com relação 
à quantidade de informação, a Internet não possui a mesma magnitude em relação à qualidade da informação disponível.

Como a Internet se tornou um importante canal e fonte de informação, os websites têm se destacado como foco de atenção, principalmente como promotores da informação.

$\mathrm{Na}$ verdade, de um modo geral, todas as organizações estão percebendo a importância do site como uma ferramenta para disseminar informação sobre suas atividades, produtos e serviços (Angigu, 2000). Segundo D’Angelo \& Little (1998), a principal razão para disponibilizar um site na Internet é comunicar e fornecer informações sobre a própria instituição. Além disso, segundo Coombs (1999), um site bem organizado pode servir como poderosa ferramenta de propaganda e disseminação da informação.

Assim, se a biblioteca se fizer presente na Internet dispondo desse recurso, deixará de ser apenas um depósito de informação e passará a ser um referencial de pesquisa, que pode ser acessado a qualquer hora, de qualquer lugar.

Schnell (1997) acredita que a Web continua a mudar a maneira de as bibliotecas oferecerem serviços, pois para atrair e conservar os seus usuários elas "têm se ocupado com o desenvolvimento de websites e novas formas de prestação de serviços eletrônicos baseados na Web”.

O website, além de ser uma ferramenta capaz de melhorar a oferta de produtos e serviços, é o melhor meio para promover e publicar os serviços oferecidos pela biblioteca (Brinkley, 1999). Por isso, é importante conhecer os fundamentos básicos para saber como utilizar seus recursos de forma a aproveitar todo o potencial da web para melhorar essa oferta de informação pelas bibliotecas.

Ao disponibilizar serviços e produtos de informação em seu website, a biblioteca se destaca em posição capaz de suprir necessidades de usuários remotos, com possibilidade de uso de mídias diferentes e serviços e produtos diferenciados como os catálogos on-line, por exemplo.

Disponibilizar produtos e serviços na Web possibilita maior interatividade entre quem oferece os produtos e serviços e os seus usuários, além de estabelecer relacionamento entre ambos. A retroalimentação por meio de sugestões e opiniões dos usuários também pode ser intensificada. Esta realidade é possível e deve ser explorada pelas bibliotecas.

O website pode ser usado também para estimular a comunicação tanto da biblioteca com os seus usuários, como dos usuários com a biblioteca.

O acesso ágil à informação das mais variadas naturezas no seu tempo preciso é uma necessidade de importância primordial, tanto para pesquisadores, estudantes, juízes, advogados, ou empresários, pois a informação certa adquire um valor incalculável no desempenho eficaz das suas diversas atividades. 
Segundo Araújo (1999/2000),

a informação, sendo considerada como um bem, aumenta de forma considerável a responsabilidade das unidades de informação, que além de exercerem seu papel habitual junto à sociedade, passam a ser componentes estratégicos no desenvolvimento da economia de qualquer nação.

D’Angelo e Little (1998) afirmam que a principal razão para colocar um site na Internet é comunicar e fornecer informações sobre a própria instituição.

Por outro lado, Bevan (1998) afirma que a razão pela qual os websites são difíceis e extremamente lentos de se utilizar, é porque as organizações sempre produzem websites com conteúdo e estrutura, que mostram informações sobre a organização, em vez de produzir websites com informações úteis para os usuários. Muitas vezes são aproveitados materiais elaborados na forma impressa, mas que precisam de adaptações para a apresentação na web. Produzir um website é aparentemente tão fácil, que nem sempre são utilizados os mesmos critérios de qualidade usados para as tradicionais formas de publicação.

Colocar um website no ar pode oferecer à biblioteca outra dimensão para alcançar usuários, que antes não faziam parte de seu universo. Mas é preciso considerar que, ao inserir-se na web, a biblioteca deve primeiramente definir seus objetivos e metas, para que não se perca dentre tantas oportunidades disponíveis nesse novo aparato tecnológico.

Apesar de todo o destaque sobre a importância do website para representar a biblioteca na web, essa nova forma de atuação da biblioteca é recente. As bibliotecas estão aprendendo sobre essa tecnologia, praticamente ao mesmo tempo em que estão criando os seus websites. Talvez por isso, os primeiros websites de bibliotecas eram basicamente uma lista de links para seus usuários, uma espécie de guia eletrônico.

Seguindo essa linha de raciocínio, estudos sobre websites de bibliotecas podem ajudar a melhorar a imagem da biblioteca, ao proporcionar melhores condições para a prestação dos serviços e para a oferta de produtos de informação.

\section{FunÇões DESEMPENHADAS PELOS Websites DE BIbLIOTECAS}

Para Bevan (1998), é necessário definir objetivos para o website, o que leva às seguintes questões: Quais são as propostas principais do website? Quem quer visitar o website está na Internet ou na intranet? Que tipo de página e informação irá atrair usuários e torná-los usuários freqüentes? Quais são as 
metas de qualidade e usabilidade que podem ser implantadas? Qual é a possibilidade de realizar esses objetivos em diferentes partes do website?

O potencial tecnológico da Web pode ser amplamente explorado pelos websites de bibliotecas no desempenho das suas diversas funções, como organizações responsáveis pelas atividades específicas da coleta, tratamento, disseminação e uso da informação de interesse do público-alvo da biblioteca representada na Internet, mais especificamente na web.

O uso dos websites em sua total potencialidade, incorporando as funcionalidades que podem ser propiciadas para facilitar o acesso e uso dos recursos informacionais pela comunidade interessada, nem sempre ocorre, até porque as funções desempenhadas pelos websites das bibliotecas são descritas na literatura de Biblioteconomia e Ciência da Informação de maneira variada.

O website pode melhorar a imagem da biblioteca, oferecendo serviços fora de seu ambiente, tais como: catálogo on-line, calendários de eventos, acesso a coleções especiais, websites da Internet de interesse de seus usuários, horário de funcionamento da biblioteca etc. (Carpenter, 1998).

Amaral e Guimarães (2002) propuseram uma classificação das funções desempenhadas pelos websites de bibliotecas, que pode ser utilizada como instrumento de marketing no planejamento, gestão e manutenção dos websites de bibliotecas. As autoras partiram do princípio que sem classificação não poderia haver nenhum pensamento humano, ação e organização que conhecemos. A classificação transforma impressões sensoriais, isoladas e incoerentes em objetos reconhecíveis e padrões recorríveis (Langridge, 1977 apud Souza, 2000).

O objetivo da classificação das funções desempenhadas pelos websites de bibliotecas é contribuir para o aprimoramento da infra-estrutura de informações da biblioteca, permitindo melhor e mais amplo aproveitamento do potencial desses websites, de acordo com a proposta de atuação da própria biblioteca na web no desempenho das funções que a biblioteca deseja cumprir. O esquema de classificação torna-se uma ferramenta de planejamento para os gestores monitorarem se o website da biblioteca está desempenhando o seu papel de acordo com o planejado. O esquema de classificação pode ser útil também para os interessados em estudar as melhores formas de estruturar, disponibilizar e, principalmente, localizar as informações que serão disponibilizadas no site, de acordo com o interesse do usuário da biblioteca em pesquisar na Internet.

São diversas as abordagens dos estudos sobre os websites de bibliotecas. Dentre os autores que classificaram as funções desses sites, podem ser mencionados Brinkley (1999); Xiao, Pixey, Cornish (1997) e Cohen e Still (1999), cujas classificações propostas apresentam algumas semelhanças e diferenças.

A classificação proposta por Amaral e Guimarães (2002) resultou da análise comparativa das propostas apresentadas pelos autores mencionados. 
Amaral e Guimarães (2002) observaram também alguns itens que poderiam indicar o desempenho pelos websites de cada uma das funções, na nova classificação que propuseram. Desta forma, a classificação das funções desempenhadas pelos websites de bibliotecas e a correspondência dos itens relativos ao desempenho de cada função ficaram estabelecidas da seguinte maneira:

1. função informacional: informações sobre a biblioteca disponíveis no website, tais como: nome da biblioteca, nome da instituição mantenedora, seções da biblioteca, equipe, notícias e novidades sobre a biblioteca, eventos realizados pela ou na biblioteca, missão da biblioteca, $e$ mail geral e setorial, telefone geral e setorial, número do fax, endereço físico, histórico, horário de funcionamento, normas e regulamentos, informações sobre as instalações físicas, estatísticas, fotos e/ou imagens da biblioteca, relação dos produtos e serviços oferecidos;

2. função promocional: uso de ferramentas promocionais da Internet existentes no website (Araújo, 1999/2000), tais como: selo com o logotipo da instituição, selo com o logotipo da biblioteca, janelas pop up com informações sobre a biblioteca, banner da biblioteca, webcasting, animações, hot site;

3. função instrucional: instruções sobre o uso dos recursos informacionais oferecidos pela biblioteca na forma tradicional e on-line disponíveis no website, tais como: FAQs (perguntas mais freqüentes), tutoriais sobre como usar serviços e produtos disponíveis no website, informações sobre como usar serviços e produtos oferecidos pela biblioteca no ambiente físico tradicional, mapa do website e instruções sobre o uso do website;

4. função referencial: links para outras fontes de informação disponíveis no website, tais como: acesso a bases de dados, links para mecanismos de busca, links para websites de outras bibliotecas, links para materiais de referência (dicionários, enciclopédias), links para periódicos eletrônicos, links para websites de instituições;

5. função de pesquisa: serviços e produtos oferecidos on-line no website da biblioteca, tais como: catálogo da biblioteca on-line, lista dos periódicos assinados pela biblioteca, serviço de empréstimo, material bibliográfico disponível on-line, serviço de reserva, serviço de referência on-line entre outros serviços on-line;

6. função de comunicação: mecanismos para estabelecer relacionamentos, tais como: formulários para cadastrar usuários, coletar opinião/satisfação pelos serviços, coletar sugestões e críticas, pesquisar opinião sobre o website, coletar sugestão de compra e link para contato com a biblioteca. 
O quadro a seguir resume, esquematicamente, a classificação proposta por Amaral e Guimarães (2002), descrevendo cada função, os itens indicativos do desempenho de cada função pelo website e a correspondência da classificação proposta com as classificações apresentadas por outros autores.

Quadro 1: Funções desempenhadas pelos websites de bibliotecas

\begin{tabular}{|c|c|c|c|}
\hline $\begin{array}{l}\text { Classificação das } \\
\text { funções propostas por } \\
\text { Amaral e Guimarães }\end{array}$ & Descrição das funções & $\begin{array}{l}\text { Fatores indicativos da } \\
\text { função no website }\end{array}$ & $\begin{array}{c}\text { Denominações apre- } \\
\text { sentadas por outros } \\
\text { autores }\end{array}$ \\
\hline Informacional & $\begin{array}{l}\text { Prover informações sobre } \\
\text { a biblioteca }\end{array}$ & $\begin{array}{l}\text { Informações sobre a bi- } \\
\text { blioteca }\end{array}$ & \begin{tabular}{|ll} 
Ferramenta informacional \\
(COHEN e STILL) \\
Informações & sobre os \\
serviços & oferecidos \\
(BRINKLEY) &
\end{tabular} \\
\hline Promocional & $\begin{array}{l}\text { Utilizar o potencial da } \\
\text { Internet para promover a } \\
\text { unidade de informação }\end{array}$ & $\begin{array}{l}\text { Uso de ferramentas pro- } \\
\text { mocionais da Internet }\end{array}$ & $\begin{array}{l}\text { Ferramenta promocional } \\
\text { (BRINKLEY) } \\
\text { Ferramenta de relações } \\
\text { públicas (XIA0, PIXEY, } \\
\text { CORNISH) }\end{array}$ \\
\hline Instrucional & $\begin{array}{l}\text { Fornecer instruções de } \\
\text { uso }\end{array}$ & $\begin{array}{l}\text { Instruções de uso da bi- } \\
\text { blioteca e seus recursos } \\
\text { informacionais }\end{array}$ & $\begin{array}{ll}\text { Ferramenta instrucional } \\
\text { (XIAO, PIXEY, CORNISH e } \\
\text { COHEN e STILL) } \\
\text { Guias de auxílio } \\
\text { (BRINKLEY) }\end{array}$ \\
\hline Referencial & $\begin{array}{l}\text { Ampliar o acesso além do } \\
\text { acervo da biblioteca }\end{array}$ & Linkpara outras fontes & $\begin{array}{l}\text { Ferramenta de referência } \\
\text { (COHEN e STILL) } \\
\text { Portal para fontes de in- } \\
\text { formações (BRINKLEY) } \\
\text { Plataforma de pesquisa } \\
\text { (XIAO, PIXEY, CORNISH) }\end{array}$ \\
\hline De Pesquisa & $\begin{array}{l}\text { Tornar disponível todos } \\
\text { os serviços e produtos }\end{array}$ & $\begin{array}{l}\text { Serviços/produtos ofere- } \\
\text { cidos on-line }\end{array}$ & $\begin{array}{l}\text { Ferramenta de pesquisa } \\
\text { (COHEN e STILL) } \\
\text { Museu/ biblioteca virtual } \\
\text { (XIAO, PIXEY, CORNISH) }\end{array}$ \\
\hline De Comunicação & $\begin{array}{l}\text { Usar a interatividade para } \\
\text { estabelecer relaciona- } \\
\text { mentos }\end{array}$ & $\begin{array}{l}\text { Uso de mecanismos para } \\
\text { estabelecer relaciona- } \\
\text { mento }\end{array}$ & $\begin{array}{l}\text { Ferramenta de comu- } \\
\text { nicação (XIAO, PIXEY, } \\
\text { CORNISH) }\end{array}$ \\
\hline
\end{tabular}

Fonte: Amaral e Guimarães (2002)

O esquema de classificação proposto pode ser aplicado em qualquer tipo de biblioteca. 


\section{Bibliotecas JURÍdicAS E WEBSITES}

Para atender seus usuários, a biblioteca deve ter um objetivo para que possa estruturar os seus recursos humanos e materiais, seus serviços e produtos. Cada tipo de biblioteca tem objetivos diferentes que implicam em práticas e serviços diferentes (Dias, 1990, p. 278).

A biblioteca especializada se distingue das outras bibliotecas pela sua ênfase em prover informação focada e especializada para uma clientela distinta, de determinada organização, em resposta às necessidades de informação de forma ágil e também antecipando necessidades de informação em áreas de conhecimento específico em que atuam. Uma biblioteca especializada visa satisfazer as necessidades da instituição à qual é vinculada. O provimento da informação é o objetivo a perseguir, de acordo com o tipo de informação específica, técnica e necessária ao órgão a que a biblioteca está vinculada, seja ele de âmbito legislativo, parlamentar, jurídico, governamental, privado; independente de sua natureza.

Pode-se então entender que a biblioteca jurídica é uma biblioteca especializada na área jurídica, que se distingue pela ênfase em prover informação direcionada, atualizada e em tempo hábil para uma clientela distinta de determinada organização, antecipando-se dentro do possível às necessidades de informação dessa clientela.

Santos (1981, p. 10) afirma que a

biblioteca jurídica é onde se reúne, analisa e indexa para estudo, leitura, pesquisa, consulta e empréstimo aos usuários especializados, os documentos referentes à doutrina, legislação, jurisprudência e os relativos a atos oficiais, normativos ou administrativos.

$\mathrm{Na}$ biblioteca jurídica, é necessário conhecer o escopo de atuação nesta área específica, o que implica no conhecimento das disposições legislativas aplicadas a casos específicos, da jurisprudência, dos preceitos jurídicos dos tribunais de justiça entre outros.

Machado (2000) afirma que a comunidade jurídica precisa manipular uma grande quantidade de informação, que se desatualiza rapidamente, e que o profissional da informação deve conhecer bem.

Uma biblioteca jurídica caracteriza-se principalmente pela urgência de seus usuários em conseguir a informação adequada na hora certa.

Santos (1981) apresenta a tipologia dos usuários da biblioteca jurídica de forma pictórica, representada na figura 1. 


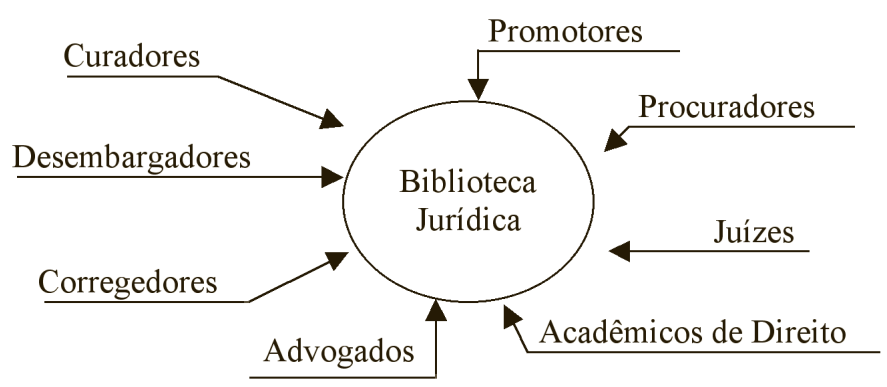

Fig. 1: Usuários da biblioteca jurídica. Fonte: Santos (1981, p. 17)

Ao se referir aos principais usuários da biblioteca jurídica, Dias (1990) lembra os advogados, os magistrados, os juristas, os pesquisadores, os legisladores, os funcionários de cartório, os tribunais, os cursos jurídicos, os professores, os estudantes e a comunidade em geral, além de desembargadores, curadores e corregedores.

Passos (2001) inclui entre os usuários da biblioteca jurídica, além dos advogados e dos juízes, os promotores, os estudantes de direito, os legisladores, os professores, dentre outros, muitos que são capazes de realizar suas próprias pesquisas. Entretanto, lembra que os usuários "recorrem ao bibliotecário jurídico para: poupar tempo [...], não incorrer erros [...] e obter pesquisas mais amplas." Assim, o bibliotecário jurídico precisa ser inovador, saber lidar com o novo e o tradicional, adaptável e principalmente disponível para atender aos seus usuários.

Uma biblioteca jurídica não pode e nem deve ser estática. Deve acompanhar a evolução da tecnologia, sendo incisiva, rápida, exata, pró-ativa na promoção da sua oferta de produtos e serviços de informação. Definir seus objetivos auxilia na avaliação e planejamento de suas atividades, pois a biblioteca jurídica caracteriza-se por ser dinâmica.

Para atender melhor aos seus usuários, a biblioteca jurídica deve abrir suas portas para a Internet e utilizar as ferramentas disponíveis que vão ao encontro de suas características em particular: informação rápida e atualizada.

Passos (2001) afirma que os bibliotecários jurídicos

sabem que páginas na web estão pobremente organizadas, ou difíceis de navegar, ou que não são atualizadas. Por causa do uso diário da Internet para encontrar informação, ele mergulha profundamente nos sites, então o bibliotecário conhece os elementos para criar com sucesso uma página na web, pois irá concentrar-se mais na boa organização, no uso fácil das informações disponibilizadas do que nos recursos gráficos e sonoros. 
Há quem afirme que a Era da informação administrativa, jurídica e financeira é o atual período histórico da humanidade, como já houve a era das grandes descobertas, a da razão e a da fé. Isso se deve ao fato de que a informação, com o auxílio dos computadores, tornou-se uma mercadoria valiosa no mundo das empresas, com reflexos na sociedade como um todo, nas escolas e na família em particular (Simcsik e Polloni, 2002, p. 63).

O objetivo de colocar o site de uma biblioteca jurídica na web é: destacar seu acervo, expandir serviços e melhorar suas operações com relação ao acesso ao crescimento de redes internas e externas de recursos eletrônicos.

A tecnologia veio para facilitar a vida dos profissionais que lidam com informações jurídicas, que se modificam quase que diariamente. Manter-se informado a respeito de decretos, medidas provisórias, resoluções, portarias, atos, instruções normativas é uma tarefa difícil, porém, a popularização dos computadores e da Internet possibilitam a atualização diária (Caldas, 1999, p.25).

\section{WEBSITES DE BIBLIOTECAS JURÍDICAS GOVERNAMENTAIS BRASILEIRAS}

No Brasil, não existe um cadastro das bibliotecas jurídicas existentes no país. No âmbito das bibliotecas do setor não governamental, a identificação dessas bibliotecas é ainda mais complexa em função da dificuldade de identificação das bibliotecas de escritórios de advocacia particulares. Por esse motivo, o estudo relatado neste artigo limitou-se às bibliotecas jurídicas governamentais. A pesquisa restringiu-se às bibliotecas do Senado Federal, da Câmara dos Deputados, Câmaras Municipais, dos Conselhos de Justiça, das Assembléias Legislativas, das Procuradorias, das Defensorias, dos Ministérios Públicos e dos Tribunais, que disponibilizavam seus websites na Internet em junho de 2003.

O cadastro das bibliotecas jurídicas governamentais brasileiras foi montado a partir de pesquisas na Internet, troca de correspondência via correio eletrônico e correio tradicional com grupos de pesquisa sobre informação e documentação jurídica, entrevistas com especialistas na área de documentação jurídica e pesquisa bibliográfica.

A partir do contato com a Federação Brasileira de Associações de Bibliotecários, Cientistas da Informação e Instituições (FEBAB), foi obtida uma lista contendo a relação dos Grupos de Informação e Documentação Jurídica (GIDJ) atuantes no Brasil. Para a elaboração do cadastro, foram enviadas cartas aos 15 GIDJs, mas apenas dois grupos responderam à correspondência.

A troca de e-mails foi feita principalmente através de fóruns de discussão disponíveis na Internet através do website Grupos (http://www.grupos.com.br). 
Foi realizada também uma entrevista com a chefe do Serviço de Apoio Técnico da Consultoria Legislativa do Senado Federal, que é responsável pela lista de discussão Infolegis, dedicada à pesquisa jurídica.

$\mathrm{Na}$ pesquisa para elaboração do cadastro foram encontradas diversas organizações com links quebrados, ou que não indicavam a existência da biblioteca da organização.

Inicialmente, o cadastro elaborado totalizou 47 bibliotecas jurídicas governamentais que possuíam websites. O registro de cada biblioteca no cadastro seguiu o modelo apresentado a seguir.

\begin{tabular}{|l|l|l|}
\hline Unidade da Federação & \multicolumn{1}{|c|}{ Entidade } & \multicolumn{1}{c|}{ Descrição } \\
\hline DF & Senado Federal -SF & $\begin{array}{l}\text { Biblioteca Acadêmico Luiz Viana Filho } \\
\text { Home page: http://www.senado.gov.br/biblioteca } \\
\end{array}$ \\
& & $\begin{array}{l}\text { E-mail: ssbib@senado.gov.br } \\
\text { Diretora: Simone Bastos Vieira }\end{array}$ \\
\hline
\end{tabular}

A observação dos websites das bibliotecas jurídicas governamentais brasileiras cadastradas para verificar o desempenho das suas funções por meio de checklist foi realizada no período de maio a junho de 2003. Durante esse período, nove websites apresentaram problemas, pois estiveram fora do ar ou modificaram sua URL, outras URLs correspondiam a links quebrados e páginas em construção impossibilitando a coleta de dados. Esses websites que não estavam disponíveis foram desconsiderados e a pesquisa ficou restrita aos 38 websites que se encontravam acessíveis.

\section{QuAIS AS FUNÇÕES DESEMPENHADAS PELOS WEBSITES DAS BIBLIOTECAS JURÍDICAS GOVERNAMENTAIS BRASILEIRAS?}

A partir da observação dos websites, com o uso de checklist testado por Amaral e Guimarães (2002), foram verificados os itens indicativos do desempenho de cada função nos websites das 38 bibliotecas jurídicas governamentais brasileiras integrantes do cadastro elaborado (Souza e Amaral, 2003). Os dados foram analisados, utilizando-se o Microsoft Excel.

A análise dos dados coletados será apresentada de acordo com o desempenho de cada uma das funções pelos websites observados. Por se tratar de uma pesquisa exploratória realizada com uma amostra não probabilística intencional, os resultados obtidos não podem ser generalizados para todo o universo de bibliotecas jurídicas governamentais brasileiras. 


\section{DESEMPENHO DA FUNÇÃO INFORMACIONAL}

Dentre os itens indicativos do desempenho da função informacional, o nome da instituição e informações sobre o acervo foram encontrados em praticamente todos os websites pesquisados, seguido da informação do horário de funcionamento da biblioteca. Foi observado se existiam 26 diferentes tipos de itens que poderiam ser considerados com indicativos do desempenho da função informativa do website Desses itens, 10 tipos estavam presentes em pelo menos metade dos websites observados. Os itens indicativos observados eram relativos a: informações sobre o nome da instituição, acervo, horário de funcionamento, e-mail geral, relação dos serviços oferecidos, telefone geral, endereço físico, nome da biblioteca, número do fax, normas e regulamentos. Treze itens obtiveram baixa freqüência de ocorrência, que eram relativas às informações sobre a relação dos produtos oferecidos, missão da biblioteca, histórico, informações sobre a participação da biblioteca em alguma rede, seções da biblioteca, informações sobre instalações físicas, fotos e/ou imagens da biblioteca, telefone setorial, equipe, e-mail setorial, eventos realizados pela ou na biblioteca, estatísticas. Em nenhum dos websites pesquisados estavam presentes todos os 26 tipos de itens indicativos de desempenho da função informacional. $\mathrm{O}$ item relativo às informações estatísticas sobre o desempenho da biblioteca não foi encontrado nos websites, portanto, apresentou ocorrência nula.

A tabela 1 resume o desempenho da função informacional pelos websites das bibliotecas pesquisados, considerando a ocorrência dos itens indicativos do desempenho dessa função.

Tabela 1 : Função informacional desempenhada pelos websites das bibliotecas jurídicas governamentais brasileiras

\begin{tabular}{|l|c|}
\hline \multicolumn{1}{|c|}{ Item indicativo da função informacional do website } & 0corrência \\
\hline Nome da instituição & 34 \\
\hline Informações sobre o acervo & 34 \\
\hline Horário de funcionamento & 30 \\
\hline e-mail geral & 27 \\
\hline Relação dos serviços oferecidos & 26 \\
\hline Telefone geral & 26 \\
\hline Endereço físico & 25 \\
\hline Nome da biblioteca & 22 \\
\hline Número do fax & 22 \\
\hline Normas e regulamentos & 19 \\
\hline Relação dos produtos oferecidos & 18 \\
\hline Missão da biblioteca & 18 \\
\hline Histórico & 17 \\
\hline Informações sobre a participação da biblioteca em alguma rede & 12 \\
\hline
\end{tabular}




\begin{tabular}{|l|c|}
\hline Seções da biblioteca & 12 \\
\hline Informações sobre instalações físicas & 10 \\
\hline Fotos e/ou imagens da biblioteca & 9 \\
\hline Notícias, novidades sobre a biblioteca & 7 \\
\hline Telefone setorial & 7 \\
\hline Equipe & 7 \\
\hline e-mail setorial & 4 \\
\hline Eventos realizados pela ou na biblioteca & 3 \\
\hline Estatísticas & 0 \\
\hline
\end{tabular}

\section{DESEMPENHO DA FUNÇÃO PROMOCIONAL}

O desempenho da função promocional pôde ser observado pela existência no website de ferramentas promocionais da Internet, consideradas itens indicativos do desempenho dessa função, conforme mostra a figura 2 .

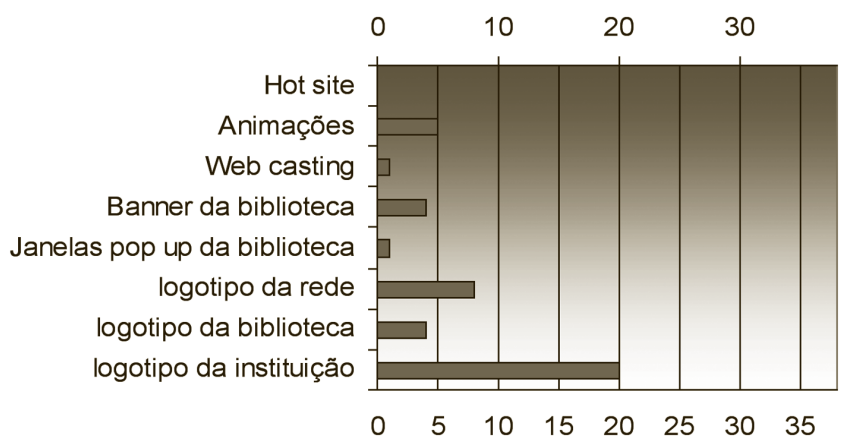

Fig. 2: Função Promocional desempenhada pelos websites das bibliotecas jurídicas governamentais brasileiras

Dentre os itens indicativos do desempenho da função promocional pelos websites das bibliotecas pesquisadas, o uso do selo com o logotipo da instituição foi observado em 20 websites, seguido pelo selo com logotipo da rede à qual a biblioteca participava, embora com freqüência de uso mais baixa que a do outro selo. Os demais itens indicativos do desempenho da função promocional pelo website, como o logotipo da biblioteca, as animações, o web casting, o banner da biblioteca e as janelas pop up obtiveram baixa freqüência de ocorrência. Nenhum dos websites pesquisados utilizava o hot site como ferramenta de promoção. As animações observadas se constituíam em figuras .GIF. As janelas pop up observadas indicavam informações sobre acervo e novos serviços e os banners tinham letreiros animados. 
Observou-se que as novas ferramentas promocionais da Internet eram pouco utilizadas nos websites das bibliotecas jurídicas governamentais brasileiras. Esse fato talvez pode estar acontecendo porque a tecnologia evolui com tamanha rapidez, que os responsáveis pelos websites não conseguem acompanhar essa evolução, pois praticamente quando aprendem a utilizá-la, a tecnologia já se tornou obsoleta.

\section{DESEMPENHO DA FUNÇÃO INSTRUCIONAL}

Com relação ao desempenho da função instrucional pelos websites observados, que foi caracterizada pelos itens existentes nos websites relativos a instruções de utilização da biblioteca e dos seus recursos informacionais, os dados são apresentados na figura a seguir.

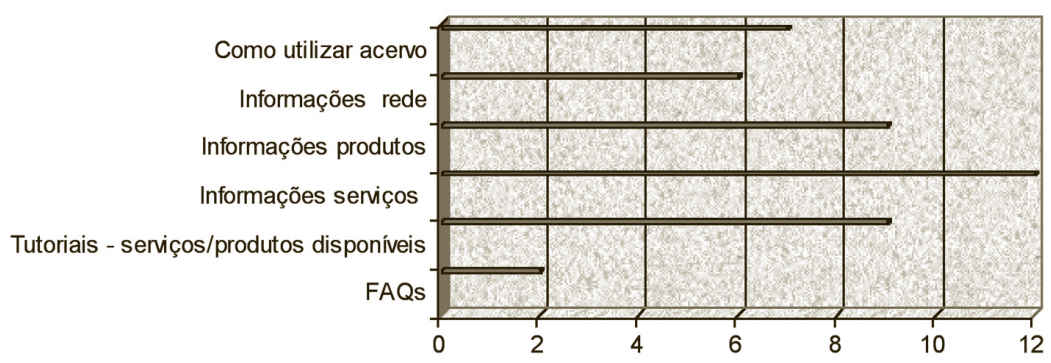

Fig.3: Função instrucional desempenhada pelos websites das bibliotecas jurídicas governamentais brasileiras

O gráfico da figura 3 permite observar que a freqüência de ocorrência de todos os itens indicativos do desempenho da função instrucional pelo website era baixa (presentes em menos da metade dos websites pesquisados), sendo que a maior freqüência era relativa ao item 'informações sobre como utilizar serviços oferecidos pela biblioteca', seguido das 'informações sobre como utilizar os produtos' e 'tutoriais de serviços e produtos disponíveis'.

Apesar do baixo índice do desempenho da função instrucional pelos websites pesquisados, foram encontrados outros itens indicativos do desempenho dessa função que não estavam relacionados no checklist utilizado para observação dos websites, como o guia da biblioteca e dispositivos para realização de visita virtual à biblioteca. 


\section{DeSEMPENHO DA FUNÇÃO REFERENCIAL}

A respeito da observação da presença de links nos websites como itens indicativos do desempenho da função referencial pelos websites, a figura 4 apresenta os resultados obtidos.

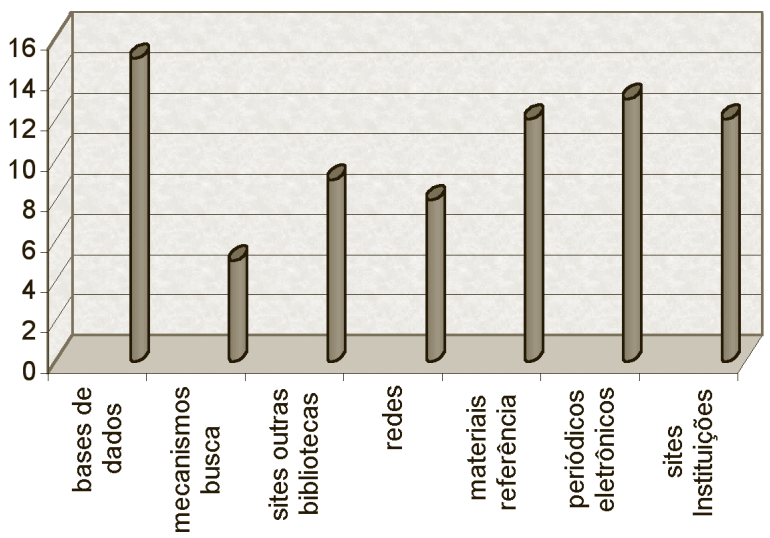

Fig. 4: Função referencial desempenhada pelos websites das bibliotecas jurídicas governamentais brasileiras

O link para acesso a bases de dados obteve a maior freqüência de ocorrência para indicar o desempenho da função referencial pelos websites pesquisados, embora tenha ocorrido em menos da metade dos websites observados. Os links para websites de outras bibliotecas, redes e mecanismos de busca apresentaram as menores freqüências de ocorrências. Entretanto, todos os websites apresentaram pelo menos um link para materiais de referência.

Portanto, o desempenho do website como porta de referência para outros websites ou recursos informacionais de interesse para os usuários da biblioteca ainda não havia sido explorado de modo satisfatório.

\section{Desempenho DA FUnÇÃo DE PESQUisa}

A freqüência de ocorrência dos itens indicativos do desempenho da função de pesquisa dos websites pesquisados, que revelavam a oferta de serviços e produtos de informação disponível on-line, pode ser observada na figura 5 . 


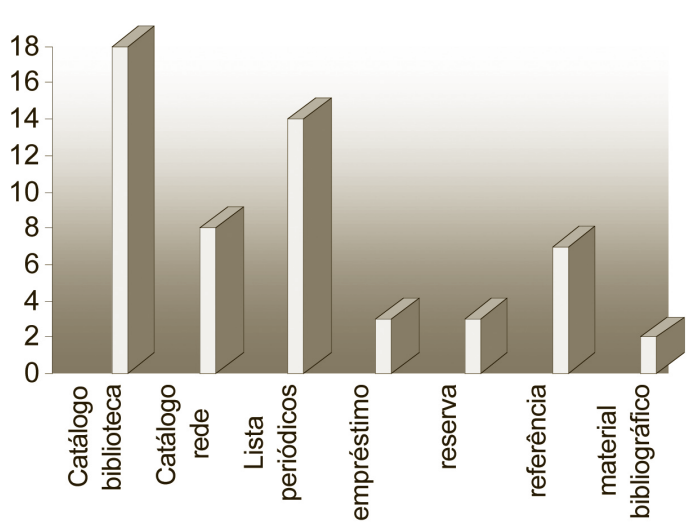

Fig. 5: Função de pesquisa desempenhada pelos websites das bibliotecas jurídicas governamentais brasileiras

O catálogo da biblioteca on-line foi o serviço oferecido por meio do website com a maior freqüência de ocorrência, uma vez que quase metade dos websites observados oferecia esse tipo de serviço de informação. Em seguida, pela ordem de freqüência de ocorrência, destacaram-se a lista de periódicos e o catálogo da rede. Nenhum item indicativo do desempenho da função listado no checklist teve ocorrência nula, embora os serviços de referência, de empréstimo, de reserva e de material bibliográfico on-line tivessem apresentado baixa freqüência de ocorrência.

Em dois websites foi registrada a necessidade de senha para acesso aos serviços da biblioteca, o que pode indicar a disponibilidade de serviços somente por meio da intranet.

Com relação ao desempenho da função de pesquisa pelo website, foram encontrados outros serviços que eram oferecidos via website da biblioteca, embora não estivessem relacionados no checklist utilizado para a observação, tais como: o serviço de Disseminação Seletiva de Informação (DSI), o de novas aquisições e o de publicações da biblioteca.

\section{Desempenho da FunÇÃo De COMUNiCAÇÃo}

A função de comunicação, cujo desempenho pôde ser verificado por meio do uso e disponibilidade no website de diversos tipos de formulários, foi verificada conforme indicado na figura 6 . 


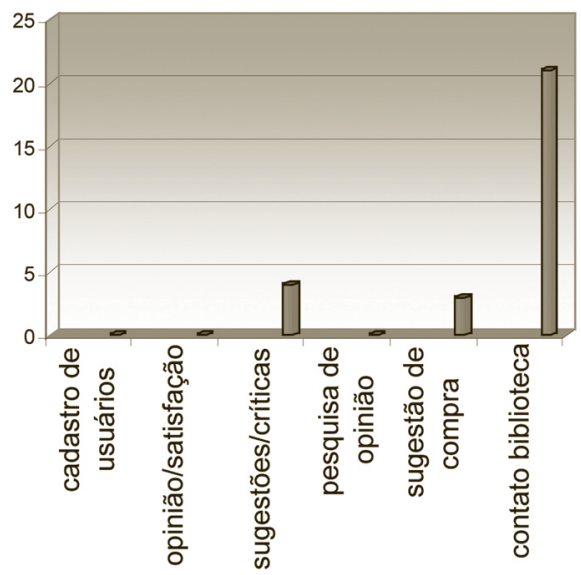

Fig. 6: Função de comunicação dos websites das bibliotecas jurídicas governamentais brasileiras

Mais da metade dos websites das bibliotecas disponibilizava um link para contato com os usuários. Contudo, poucos websites disponibilizavam formulários para envio de sugestões e críticas e sugestões de compra. Os outros itens indicativos do desempenho da função de comunicação pelo website, tais como: formulário para cadastro de usuários, para pesquisa de opinião e nível de satisfação relativo aos serviços prestados e de pesquisa de opinião sobre o website obtiveram ocorrência nula.

Embora a biblioteca não tenha sido consultada para apresentar justificativas que explicassem o índice de desempenho praticamente nulo da função de comunicação, não se pode imaginar que o potencial tecnológico da Internet não seja explorado para exercitar o relacionamento entre a biblioteca e os seus usuários, pois essa comunicação pode estar sendo praticada mais intensamente pela intranet, e essa questão não foi abordada pela pesquisa.

\section{CONSIDERAÇÕES FINAIS}

A tecnologia sempre foi uma ferramenta muito poderosa para o acesso à informação, principalmente quando a informação assume a importância do seu papel estratégico na evolução da sociedade. A área jurídica, devido a sua constante produção de informação e a necessidade de atualização para acompanhar essa produção, deve aproveitar da melhor forma possível as funcionalidades que a Internet apresenta. Nesse sentido, os estudos sobre websites são relevantes para se conhecer as possibilidades do uso desse canal de comunicação em toda sua potencialidade em prol da evolução social. 
No âmbito da Ciência da Informação ainda são poucos os estudos sobre as funcionalidades que os websites de bibliotecas podem oferecer e a evolução pela qual a biblioteca tem passado em razão dessas novas tecnologias.

É imprescindível que a biblioteca esteja a par das inovações oferecidas pela Internet, ao acompanhar a evolução da tecnologia, para que não perca de vista o uso do potencial da web para organizar e facilitar o acesso à informação, principalmente no contexto do planejamento, gestão e manutenção dos websites que representam a biblioteca.

Os resultados da análise dos dados coletados na observação destacaram níveis diferenciados do desempenho das funções pelos websites das bibliotecas jurídicas governamentais brasileiras que foram pesquisados. A função informacional destacou-se como a de maior presença de itens indicativos do seu desempenho, embora grande parte dos websites observados disponibilizasse apenas informações sobre as atividades da biblioteca em seu ambiente físico de prestação de serviços.

Foram verificados indícios da disponibilidade de serviços pela intranet, que podem ser estudados em novas pesquisas.

Os itens do checklist de menor freqüência de ocorrência ou que obtiveram ocorrência nula deverão ser observados mais detalhadamente em futuras pesquisas, na tentativa de verificar se estão ocorrendo avanços na oferta dos serviços e produtos de informação disponível nos websites das bibliotecas jurídicas governamentais brasileiras.

Como o índice de desempenho da função de comunicação pelos websites observados foi baixo, ainda que resguardadas as limitações deste estudo, talvez as bibliotecas jurídicas governamentais brasileiras pesquisadas não estejam utilizando o potencial dos seus websites como ferramenta de comunicação para fortalecer o relacionamento com a sua clientela e com os seus diversos tipos de públicos. A comunicação com esses públicos para pesquisar suas opiniões sobre o desempenho da biblioteca como prestadora de serviços de informação pode contribuir no aprimoramento da forma de prestar serviços e oferecer produtos de informação aos seus usuários,.

O checklist utilizado demonstrou-se adequado para a realização da pesquisa. Ter sido complementado com o acréscimo de alguns itens indicativos de desempenho de função pelos websites, de acordo com a observação realizada, facilitará e aprimorará o seu uso em futuras pesquisas.

O uso do checklist como ferramenta de planejamento para auxiliar os gestores das bibliotecas poderá contribuir para a verificação do desempenho do seu website, no sentido de verificar como e com que intensidade o potencial do website está sendo aproveitado pela biblioteca no desempenho de cada uma das funções conforme planejado. 
Salvo raras exceções, de modo geral, a presença das bibliotecas jurídicas governamentais brasileiras na web ainda não era expressiva. É recomendável, portanto, que essas bibliotecas explorem mais a potencialidade dos recursos da web para ampliar a prestação dos seus serviços , o que as tornará mais visíveis para os seus usuários.

\section{REFERÊNCIAS}

Amaral, Sueli Angélica do; Guimarães, Tatiara Paranhos. Funções desempenhadas pelos sites das bibliotecas universitárias do Distrito Federal, Brasil. In: Congresso Brasileiro de Biblioteconomia e Documentação e Ciência da Informação, 20. Fortaleza, 2002. Anais. CD

Amaral, Sueli Angélica do; Guimarães, Tatiara Paranhos. Sites das bibliotecas universitárias brasileiras: estudo das funções desempenhadas. In: Seminário Nacional de Bibliotecas universitárias, 12. Recife, 2002. Anais CD

Angigu, B. O. Library web sites at historcally Black Colleges and Universities. College and Research Libraries, v. 61, n. 1, p. 30-37, Jan. 2000.

Araújo, Wagner Junqueira de. Ferramentas para promoção em web sites de unidades de informação. Revista de biblioteconomia de Brasília, v. 23/24, p. 89-108, especial, 1999/2000.

Bevan, N. Usability issues in web site design. 1998. Disponível em: $<$ http://www.npl.co.uk/npl/sections/us>. Acesso em 17 out. 2004.

Brinkley, M. The library Web site in 1999: a virtual trip to the library. Internet Librarian and Libtech International 99. Proceedings. London, 29-31. March 1999. Edited by Carol Nixon and Heide Dengler. Medford, New Jersey: Information Today, Inc., 1999, p.8-15.

Caldas, Simone. Biblioteca virtual para acompanhar o pique das reformas. Revista Anamatra, v. 11, n. 36, p. 25-26, maio 1999.

Carpenter, Beth. Your atention, please!: marketing today s libraries. Computers in libraries, v. 18, n. 8, p. 62-66, Sept. 1998.

Chaim, Ricardo Matos. Estratégias de marketing na Internet para websites de periódicos brasileiros em ciência da informação. 2001. 83f. Dissertação (Mestrado em Ciência da Informação) - Universidade de Brasília. Departamento de Ciência da Informação e Documentação, Brasília.

Cohen, Laura, B., Still, Julie, M. A comparison of research university and two-year college library web sites: content, functionality, and form. College and Research Libraries, v. 60, n. 3, p. 275-289, May 1999. 
Coombs, M. Web site design evaluation for public libraries: a markeitng tool for the new millennium. The Australian Library Journal, v. 48, n. 2, p. 117-127, May 1999.

D’ Angelo, J.; Litlle, S.K. Succesfull web pages: what are they and do they exist? Information Technology and Libraries, v. 17, n. 2, p. 7178, June 1998.

Dias, Eduardo José Wense. A biblioteca legislativa e seus objetivos. Revista de Informação Legislativa, Brasília, v. 27, n. 107, p.277-286, jul./set. 1990.

Machado, Maria Tereza Ferlini. Relacionamento Biblioteca/usuário : fator relevante no processo de disseminação da informação jurídica. In: Congresso Brasileiro de Biblioteconomia e Documentação, 19. Porto Alegre, 2000. Anais. CD-ROM.

Passos, Edilenice. Bibliotecário jurídico: seu papel, seu perfil. Apresentado no III Encontro de Informação e Documentação Jurídica, Rio de Janeiro, RJ, 2001. Disponível em http://www.infolegis. com.br/perfilbibjuridico.htm. Acessado em 16 fev. 2003.

Santos, Maria dos Remédios Ribeiro. Elementos básicos para organização de uma biblioteca jurídica. São Luís, 1981. 38 f. Trabalho apresentado à banca examinadora do concurso para ingresso na carreira do magistério, no campo específico de conhecimento: organização e administração de bibliotecas e sistemas de documentação do Departamento de Biblioteconomia do Centro de Ciências Sociais da Universidade Federal do Maranhão.

Schnell, Eric. Writing for the Web: a primer for librarians. Disponível em: http://www.bonesmed.drio-state.edu/eric/papers.primer/weddoc.html/. Acesso em 7 de julho de 2001.

Silva, Terezinha Elisabeth da; Tomaél, Maria Inês. Fontes de informação na internet: a literatura em evidência. In: Tomaél, Maria Inês; Valentim, Marta Lígia Pomim. (Org.). Avaliação de fontes de informação na internet. Londrina : Eduel, 2004. Introdução, p. 1-18.

Simcsik, Tibor; Polloni, Enrico Giulio Franco. Tecnologia da informação automatizada. São Paulo : Berkeley Brasil, 2002. ISBN 8572516336.

Sociedade da Informação no Brasil: livro verde. Organizado por Tadao Takahashi. Brasília: Ministério da Ciência e Tecnologia, 2000. 203p.

Souza, Katyusha Madureira Loures de; Amaral, Sueli Angélica do. Funções desempenhadas pelos sites das bibliotecas jurídicas governamentais do Brasil. In: Congresso de Iniciação Científica da Universidade de Brasília, 9. Brasília, 2003. Anais.

Souza, Rosali Fernandez de. A classificação como interface da Internet. DataGramaZero : revista de ciência da informação, v. 2, n. 2, abr. 2000 .

Silva, Terezinha Elisabeth; Tomaél, Maria Inês. Fontes de informação na internet: a literatura em evidência. In: Tomaél, Maria Inês; Valentim, Marta Lígia Pomim (org.). Avaliação de fontes de informação na Internet. Londrina : Eduel, 2004. 155p. cap. 1, p.1-17. 


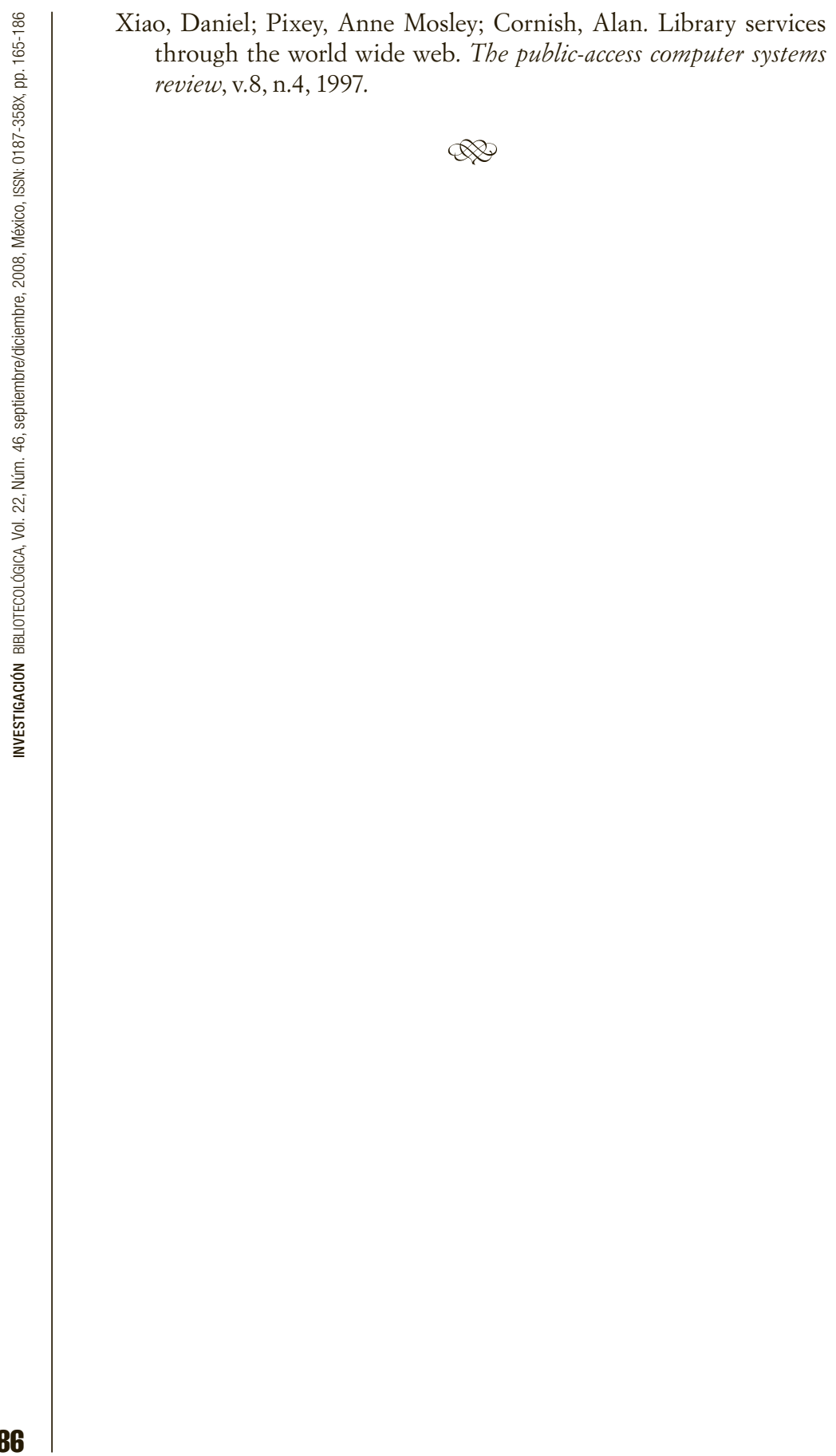

